\title{
Grape Leaves as a Natural Antioxidant Source: Determination of Total Phenolic Compound Changes
}

\author{
Zehra Babalık ${ }^{1, a, *}$, Nilgün Göktürk Baydar ${ }^{2, b}$ \\ ${ }^{I}$ Department of Plant and Animal Production, Atabey Vocational School, Isparta University of Applied Sciences, 32670 Isparta, Turkey \\ ${ }^{2}$ Department of Agricultural Biotechnology, Faculty of Agricultural Sciences and Technologies, Isparta University of Applied Sciences, 32670 Isparta, Turkey \\ *Corresponding author

\begin{tabular}{l|l}
\hline A R T I C L E I N F O & A B S T R A C T \\
\hline Research Article & $\begin{array}{l}\text { In this study, total phenolic compounds which possess health-promoting effects and provide basic } \\
\text { nutrition were aimed to determine the alterations in different grapevine leaves. Total phenolic } \\
\text { content was determined using Folin-Ciocalteu colorimetric method by using a spectrophotometer. } \\
\text { At the result of the study, it was determined that contents of total phenolic in leaves collected from } \\
\text { different grape cultivars were varied to cultivars and grape leaves had high phenolic compounds as } \\
\text { berries. Therefore the grape leaves especially wine grapes such as Narince, Bogazkere ve Kalecik } \\
\text { Karasi may be used as an easily accessible source of natural antioxidants and food supplement at } \\
\text { pharmaceutical and food industry. }\end{array}$
\end{tabular}

Keywords:

Antioxidant

Grapevine

Total phenolic

Leaves

Vitis vinifera

Türk Tarım - Gıda Bilim ve Teknoloji Dergisi 7(10): 1603-1606, 2019

\section{Doğal Antioksidan Kaynağı Olarak Üzüm Yaprakları: Toplam Fenolik Madde Değişimlerinin Belirlenmesi}

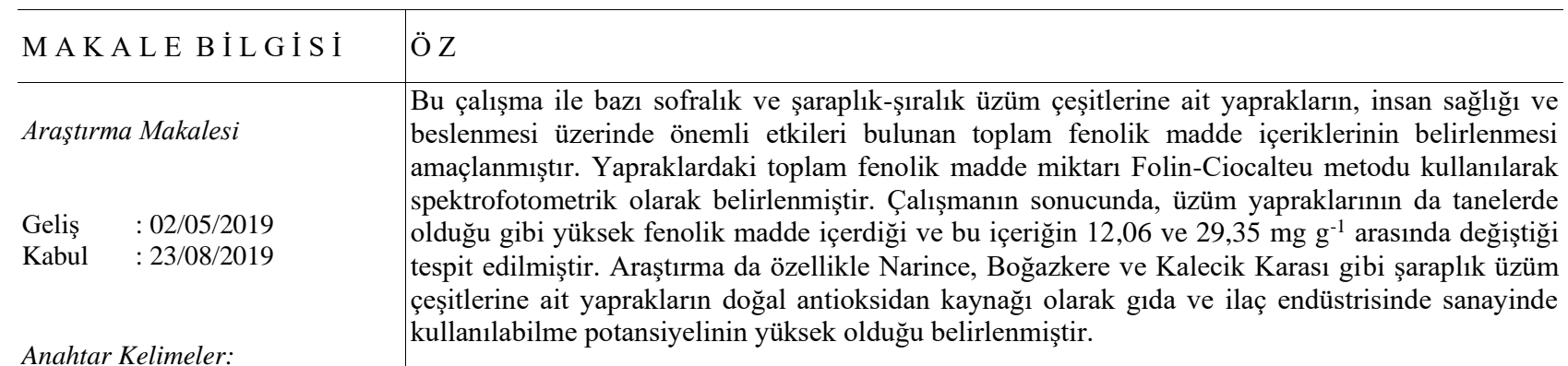

Antioksidan

Asma

Toplam fenolik

Yaprak

Vitis vinifera 


\section{Giriş}

Gerek Türkiye'de ve gerekse Dünyada ekonomik önemi yüksek meyve türlerinden birisi olan üzüm, dünyada toplam 74.276.583 ton (\%52'si şaraplık, \%42'si sofralık ve $\% 7$ 'si kurutmalık) ülkemizde ise 4.200 .000 ton (\%57'si sofralık, \%40'1 kurutmalık ve \%2'si şaraplık) olarak üretilmektedir (Anonim, 2018; FAO, 2019). Özellikle son yıllarda besin içeriği yüksek olduğu bilinen üzümün, aynı zamanda insan sağlığ üzerine de son derece olumlu etkileri olduğunun ortaya konulması, üzüm ve üzüm ürünlerinin oldukça popüler bir konuma gelmesine neden olmuştur.

Üzüm güçlü antioksidan etki göstererek insan vücuduna zararlı etkileri olan ve çok çeşitli hastalıkların oluşumuna neden olan serbest radikalleri kendilerine bağlayan ve onların zararlarını azaltan-engelleyen bileşikler bakımından son derece zengin bir meyvedir (Khalil ve ark., 2007). Bu nedenle tane, kabuk, posa, çekirdek gibi üzümün farklı kısımlarından ekstrakte edilen doğal antioksidan maddeler, günümüzde kozmetik ürünlerde, ilaçların bileşimde, katkı maddesi olarak gidalarda kullanılmakta ve besin takviyesi olarak tabletler şeklinde eczane raflarında yer almaktadırlar (Makris ve ark., 2007; Doshi ve ark., 2006). Tüm bunların yanı sıra, ülkemizin de içinde yer aldığı pek çok Akdeniz ülkesinde, özellikle halk hekimliğinde, asma yapraklarının da çeşitli hastalıkların tedavisi için (hepatit, karın ağrıları, ishal, antihemoroid, antiseptikantianemi, idrar söktürücü) gıda ve ilaç olarak kullanıldığı bilinmektedir (Bombardelli ve Morazzoni, 1995; Baytop, 1999; Orhan ve ark., 2006). Yapılan farmakolojik çalışmalarda yaprakların antidiyabetik, antioksidan (Orhan ve ark., 2006), antibakteriyel (Mansour ve ark., 2011), antileishmanial (Kong ve ark., 2003) ve peroksitin zarar görmesine karşı nöro-koruyucu potansiyele sahip olduğunu göstermektedir (Dani ve ark., 2010). Nitekim son yirmi yıldan bu yana, bu konu birçok ilaç firmasının dikkatini çekmiş olup, etkili ve güvenli bir fenol kaynağı bulma yönünde ekonomik anlamda büyük çaba sarf etmelerine neden olmuştur (Gurib-Fakim, 2006; Boudet, 2007).

Üzümlerde bulunan en önemli aktif bileşenler olan fenolik bileşikler (Tang ve Chan, 2014), antioksidan ve antiradikal özellikleri son derece yüksek olan bileşiklerdir (Lu ve Foo, 2001; Murty ve ark., 2002). Asmanın fenolik bileşik profilinin belirlenmesi amacıyla yapılan çalışmalar incelendiğinde bunların büyük çoğunluğunun üzüm ve üzüm ürünleri üzerinde yoğunlaştığı (Lu ve Foo, 2001; Murthy ve ark., 2002; Göktürk Baydar ve ark., 2011; ElKassas ve ark., 2014) ancak, asma yaprakları üzerine yapılan araştırmaların ise çok daha kısıtlı olduğu görülmektedir (Pari ve ark., 2007; Amarowicz ve ark., 2008; Park ve Cha, 2008; Hallaç Türk, 2009; Jaradat ve ark., 2017). Bu nedenle bu çalışma ile 12 farklı üzüm çeşidine ait asma yapraklarının gıda ve ilaç sektöründe değerli bir kaynak olarak kullanılabilme potansiyelinin ortaya koyulabilmesi bakımından toplam fenolik madde içeriklerinin belirlenmesi amaçlanmıştır.

\section{Materyal ve Metot}

Çalışma Isparta Tarım Bilimleri ve Teknolojileri Fakültesine ait bağda bulunan omcalar üzerinde yürütülmüştür. Bağın bulunduğu Isparta ilinin uzun yıllar (1950-2018) yıllık ortalama yağış miktarı $550,5 \mathrm{~kg} \mathrm{~m}^{-2}$, yıllık ortalama sıcaklık değeri $12,2^{\circ} \mathrm{C}$ ve yıllık ortalama nem miktarı ise \%60,9'dur (Anonim, 2019). Deneme alanı kumlu-tınlı toprak yapısına sahip olup, pH's1 8,43, kireç içeriği \%28,84, EC'si $0,15 \mathrm{dS} \mathrm{m}^{-1}$ ve organik madde içeriği \%1,44'dür.

Çalışmada bitkisel materyal olarak; 13 yaşlı, kordon terbiye şekli verilmiş, sıra üzeri ve sıra arası mesafesi $1,5 \times 3 \mathrm{~m}$ olan $1103 \mathrm{P}$ anacı üzerine aşılı Boğazkere, Cabernet Sauvignon, Kalecik Karası, Öküzgözü, Alphonse Lavallée, Cardinal, Horoz Karas1, Italia, Michael Palieri, Red Globe, Sultani çekirdeksiz ve Narince üzüm çeşitlerine ait yapraklar kullanılmıştır. Araştırmada kullanılan yapraklar sağlıklı omcaların alt boğumdan itibaren 6. ile 12. boğumlar arasından, mümkün olduğunca aynı pozisyon ve yönden toplanmıştır (Hallaç, 2009). Toplanan yapraklar toplam fenolik madde analizinde kullanılmak üzere hemen Tarım Bilimleri ve Teknolojileri Fakültesi laboratuvarına getirilerek saf su ile yıkanmış ve ardından $45^{\circ} \mathrm{C}$ 'lik etüvde kurutularak toz haline getirilmiş ve analiz yapılıncaya kadar desikatörde bekletilmiştir.

\section{Fenolik Bileşik Ekstraksiyonu}

Kurutulup blendarda toz haline getirilen 0,5 g yaprak üzerine, $5 \mathrm{ml} \% 0,1 \mathrm{HCl}$ içeren \%70'lik metanol eklenmiş ve vortekslendikten sonra, ultrasonik su banyosunda bekletilmiştir. $4000 \mathrm{rpm}$ de santrifüjlendikten sonra, süpernetant kısmı temiz bir tüpe alışmıştır. Ekstraksiyon aynı şekilde bir kez daha tekrarlanmış ve bir araya getirilen süpernetantların hacmi HCl-methanol ile 10 ml'ye tamamlanmıştır. Ardından içinde fenolik bileşikleri bulunduran bu ekstraktlar $0,45 \mu \mathrm{m}$ 'lik filtreden geçirilerek, analizlerde kullanılmıştır.

\section{Toplam Fenolik Madde Miktarının Belirlenmesi}

Toplam fenolik madde miktarı Singleton ve Rossi (1965)'ye göre Folin-Ciocalteu kolorimetrik metodu kullanılarak gerçekleştirilmiştir. Kalibrasyon eğrisinin oluşturulmasında referans standart olarak gallik asit (Sigma) kullanılmıştır. Analizler elde edilen ekstraktın saf su ile seyreltilmiş Folin-Ciocalteu reaktifi ile karıştırılmasının ardından, doymuş sodyum karbonat çözeltisi ile nötralize edilmiştir. Karışım oda sıcaklığında 2 saat boyunca bekletildikten sonra, elde edilen mavi renkli karşımın absorbansı T70 Plus Dual Beam (Arlington, USA) marka spektrofotometre ile 765 nm'de okunmuştur. Örneklerin toplam fenolik madde içerikleri, gallik asitle hazırlanan standart bir eğrinin lineer denkleminden yararlanılarak belirlenmiştir. Sonuçlar gallik asit eşdeğeri (GA) olarak mg g-1 kuru yaprak ağırlığı şeklinde hesaplanmıştır.

\section{Istatistiksel Analiz}

Araştırmada elde edilen verilerin değerlendirilmesinde SPSS 16 paket programı kullanılmış olup, ortalamalar arasındaki farklılıklar Duncan çoklu karşılaştırma testi ile ifade edilmiştir.

\section{Bulgular ve Tartışma}

Farklı üzüm çeşitlerine ait yaprakların toplam fenolik madde içeriklerinin belirlenmesine yönelik gerçekleştirilen araştırma sonucunda elde edilen bulgular Şekil 1'de sunulmuştur. Elde edilen veriler incelendiğinde, çeşitler 
arasındaki toplam fenolik madde miktarının istatistik olarak önemli ölçüde değişim gösterdiği belirlenmiştir $(\mathrm{P} \leq 0,05)$. Yapılan değerlendirmelerde çeşitler arasındaki toplam fenolik madde miktarlarının 12,06 ve $29,35 \mathrm{mg} \mathrm{g}^{-1}$ arasında değiştiği tespit edilirken, en yüksek fenolik madde miktarı Narince $\left(29,35 \mathrm{mg} \mathrm{g}^{-1}\right)$, Boğazkere $\left(28,58 \mathrm{mg} \mathrm{g}^{-1}\right)$, Kalecik Karası $\left(28,25 \mathrm{mg} \mathrm{g}^{-1}\right)$ ve Sultani Çekirdeksiz $\left(26,88 \mathrm{mg} \mathrm{g}^{-1}\right)$ üzüm çeşitlerinden elde edilmiştir. Italia ve Cabernet Sauvignon üzüm çeşitlerinin ise sırasıyla 12,06 ve $14,34 \mathrm{mg} \mathrm{g}^{-1}$ ile en düşük toplam fenolik madde miktarına sahip oldukları tespit edilmiştir. Emir, Kalecik Karası ve Narince üzüm çeşitlerinde toplam fenolik madde miktarını inceleyen Göktürk (2006), toplam fenolik maddenin, çeşitler arasında gallik asit cinsinden 73,79$142,79 \mathrm{mg} \mathrm{g}^{-1}$ olarak belirlemiş ve bizim de çalışmamızda olduğu gibi Narince çeşidinin en yüksek toplam fenolik madde miktarına sahip olduğunu saptanmıştır. Hallaç (2009), Barış, Italia, Tekirdağ Çekirdeksizi, Trakya İlkeren ve Yalova İncisi üzüm çeşitlerinden alınan yaprak örneklerindeki toplam fenolik madde miktarının kateşin cinsinden 5,88-10,57 $\mathrm{mg} \mathrm{g}^{-1}$ (KA) olarak belirlerken, Güler ve Candemir (2014) Sultani Çekirdeksiz, Sultan1, Sultan7, Saruhanbey ve Narince üzüm çeşitlerine ait yapraklardaki toplam fenolik miktarının ise 9,72-14,22 $\mathrm{mg} \mathrm{g}^{-1}$ (YA) olarak tespit etmişlerdir. Durmaz ve ark. (2007) ise, bazı yenilebilir yapraklardaki toplam fenolik madde içeriklerinin $0,25-14,22 \mathrm{mg}^{-1}$ arasında değiştiğini bildirmişlerdir. Çalışmalarında bizimle aynı metodu (Singleton ve Rossi, 1965) kullanan bu araştırıcıların dışında, Amarowicz ve ark. (2008) çalışmalarında Naczk ve Shahidi (1989)'nin toplam fenolik metodunu kullanmış ve Chasselas Rose üzüm çeşidine ait yapraklardaki fenolik madde içeriğinin $63,3-72,8 \mathrm{mg} \mathrm{g}^{-1}$ arasında değiştiğini bildirmişlerdir. Asma yapraklarının fenolik bileşiklerce zengin olması, bunların gida sanayinde doğal antioksidan olarak değerlendirilebileceği gerçeğini de ortaya çıkarmaktadır (Doshi ve ark., 2006). Nitekim çalışmamızda elde edilen sonuçlarda bu görüşü destekler niteliktedir.

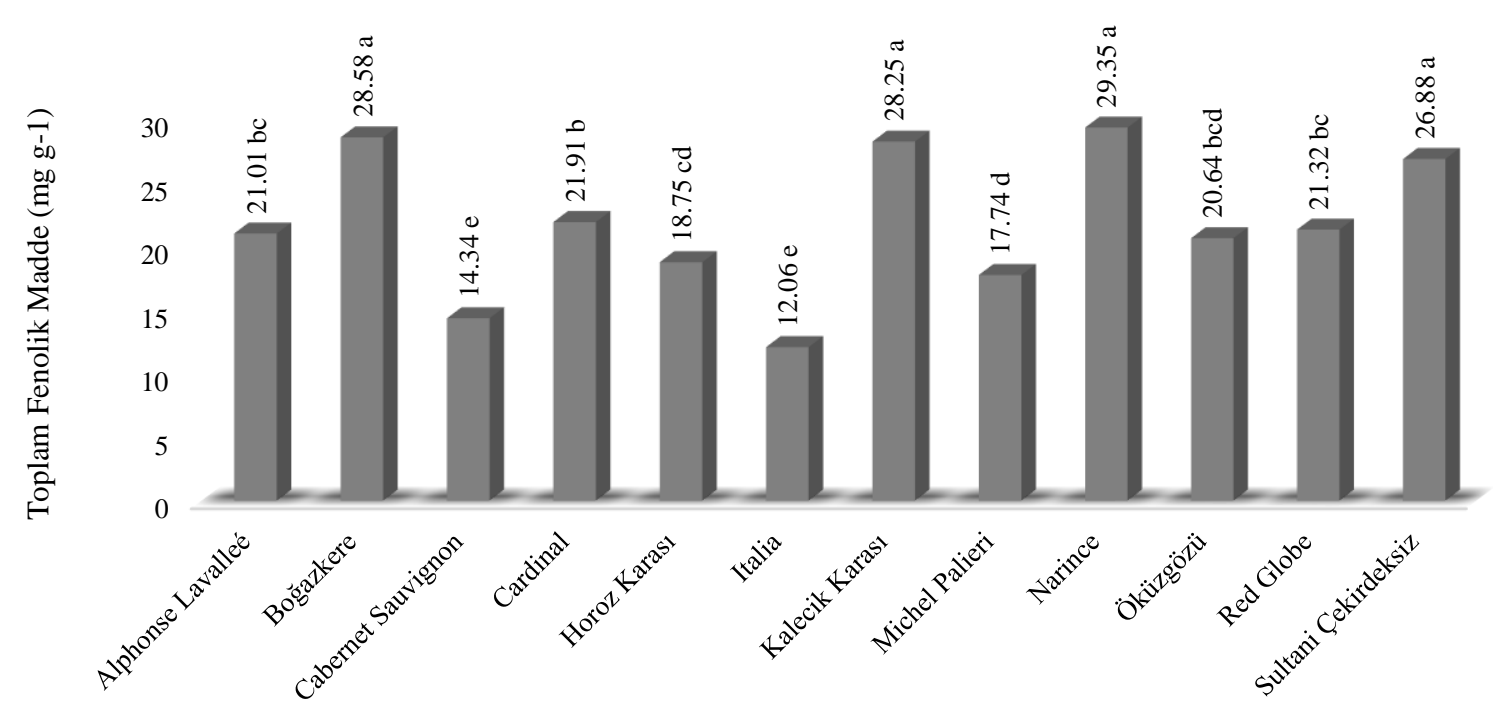

Şekil 1 Farklı üzüm çeşitlerine ait yaprakların toplam fenolik madde içerikleri Figure 1 Total phenolic content of different grape varieties

Asma yapraklarının bugüne kadar bilinen fitokimyasal bileşenleri izoprenoitler, organik asitler, steroidler, antosiyaninler, steroller, lökoantosiyaninler, rutin, kuersitrin, izolasitrosit, kanferol, luteolilitinler, serbest yağlar, serbest yağ asitleri ve heterosiklik bileşikler olarak belirlenmiştir (Jaradat ve ark., 2017). Asma yapraklarının özellikle antioksidan özellik gösteren fenolik bileşikler bakımından kaynak olabileceğinin ortaya konması (Pari ve ark., 2007; Amarowicz ve ark., 2008), farklı tür ve çeşitlere ait yapraklardan elde edilen ekstraktların, ilaç sanayi ve gıda sektöründe kullanılmak üzere analiz edilmesine sebep olmuş ve bu durum son yıllarda yaprak fenoliklerinin belirlenmesine yönelik çalışmaların ağırlık kazanmasına neden olmuştur. Nitekim Jaradat ve ark. (2017) günümüzde en iyi nutrasötik ve sağlıkla ilgili değerler elde etmek için, antioksidan durumundaki değişiklikleri, toplam fenolik madde ve flavonoidlerdeki değişiklikleri bilmenin çok büyük önem taşıdığını belirtmiştir.

\section{Sonuç}

Analitik bulgular sonucunda üzüm yapraklarınında tanelerde olduğu gibi yüksek fenolik madde içerdiği ve bu içeriğin çeşitler arasında önemli ölçüde değişim gösterdiği belirlenmiştir. Bu durum üzüm yapraklarının, zengin bir doğal fenolik-antioksidan kaynağı olduğunu göstermektedir. Çalışmanın sonunca, Narince, Boğazkere ve Kalecik Karası gibi şaraplık üzüm çeşitlerine ait yaprakların gıda endüstrisinde ve ilaç sanayisinde fonksiyonel bileşenler olarak kullanılabilme potansiyelinin yüksek olduğu belirlenmiştir.

\section{Kaynaklar}

Amarowicz R, Narolewska O, Karamac M, Kosinska A, Weidner S. 2008. Grapevine leaves as a source of natural antioxidants. Polish Journal of Food and Nutrition Sciences, 58(1). 
Anonim, 2018. 2018 World Vitiviniculture Situation. OIV Statistical Report on World Vitiviniculture. http://www.oiv.int/public/medias/6371/oiv-statistical-reporton-world-vitiviniculture-2018.pdf. Erişim tarihi: 21.07.2019.

Anonim, 2019. Tarım ve Orman Bakanlığı, Meteoroloji Genel Müdürlüğü.

Baytop T. 1999. Therapy with medicinal plants in turkey (Past and present). Istanbul University, Turkey.

Bombardelli E, Morazzoni P. 1995. Vitis vinifera L. Fitoterapia. 66: 291-317.

Boudet AM. 2007. Evolution and current status of research in phenolic compounds. Phytochem 68: 2722-35.

Dani C, Oliboni L, Agostini F, Funchal C, Serafini L, Henriques JA, Salvador M. 2010. Phenolic content of grapevine leaves (Vitis labrusca var. Bordo) and its neuroprotective effect against peroxide damage. Toxicol In Vitro 2010; 24: 148-53.

Doshi P, Adsule P, Banarjee K. 2006. Phenolic composition and antioxidant activity in grapevine partsand berries (Vitis vinifera L.) cv. Kishmish Chornyi (Sharad Seedless) during maturation. International Journal of Food Science and Technology 2006, 41 (Supplement 1): 1-9

Durmaz G, Cam M, Kutlu T. 2007. Antioxidant activities of some edible leaves. Book of Abstracts of the $2^{\text {nd }}$ International Congress on Food and Nutrition, 24-26 October 2007 , Istanbul, Turkey, p. 34.

El-Kassas FB, Ali AM, Mostafa SE. 2014. Phenolic compounds as antioxidants of some products manufactured from two cultivated Egyptian varieties of seedless grapes. Annals of Agricultural Sciences, 59(2): 195-199.

FAO 2019. Food and Agriculture Organization of the United Nations. http://www.fao.org.tr (Accessed to web: 16.04.2019)

Göktürk BN, 2006. Organic Acids, Tocopherols and Phenolic Compositions of Some Turkish Grape Cultivars. Chemistry of Natural Compounds, 42:2,156-159.

Göktürk BN., Babalık, Z., Hallaç Türk, F., Çetin, E. S. 2011. Phenolic composition and antioxidant activities of wines and extracts of some grape varieties grown in Turkey. Journal of Agricultural Sciences. 17: 67-76.

Gurib-Fakim A. 2006. Medicinal plants: Traditions of yesterday and drugs of tomorrow. Mol Aspects Med; 27: 1-93.

Güler A, Candemir A. 2014. Total phenolic and flavonoid contents, phenolic compositions and color properties of fresh grape leaves. Türk Tarım ve Doğa Bilimleri Dergisi, 1(Özel Say1-1): 778-782.

Hallaç TF. 2009. Bazı sofralık üzüm çeşitlerinde farklı dönemlerde alınan yapraklardaki fenolik ve mineral madde değişimlerinin belirlenmesi. SDÜ Fen Bilimleri Enstitüsü Doktora Tezi. 113 sayfa.
Jaradat NA, Zaid AN, Hussen F, Ali I. 2017. The effects of preservation methods of grapevine leaves on total phenols, total flavonoids and antioxidant activity. Marmara Pharmaceutical Journal, 21(2): 291-297

Khalil MY, Moustafa AA, Naguib NY. 2007. Growth, phenolic compounds and antioxidant activity of some medicinal plants grown under organic farming condition", World Journal of Agricultural Sciences, 3(4): 451-457.

Kong JM, Chia L-S, Goh NK, Chia TF, Brouillard R. 2003. Analysis and biological activities of anthocyanins. Phytochem, 64: 923-33.

Lu Y, Foo YL. 2001. Antioxidant Activities of Polyphenols from Sage (Salvia officinalis). Food Chemistry, 75: 197-202.

Makris DP, Boskou G, Andrikopoulos NK. 2007. Polyphenolic content and in vitro antioxidant characteristics of wine industry and other agri-food solid waste extracts. J Food Compos Anal 20: 125-132.

Mansour R, Ayed L, Hammami S, Mighri Z, Bakhrouf A, Mhenni F. 2011. Dyeing properties and antibacterial activities of the extracts of Vitis vinifera L. leaves,Tunisia. Tunisian J Med Plants Nat Prod; 6: 126-32.

Murthy KNC, Singh RP, Jayaprakasha GK. 2002. Antioxidant Activity of Grape (Vitis vinifera) Pomace Extracts. Journal of Agricultural and Food Chemistry, 50: 5909-5914.

Naczk M, Shahidi F. 1989. The effect of methanol-ammoniawater treatment on the content of phenolic acids of canola. Food Chemistry, 31: 159-164.

Orhan N, Aslan M, Orhan DD, Ergun F, Yesilada E. 2006. Invivo assessment of antidiabetic and antioxidant activities of grapevine leaves (Vitis vinifera) in diabetic rats. J Ethnopharmacol. 108: 280-286.

Pari L, Karamać M, Kosińska A, Rybarczyk A, Amarowicz R. 2007. Antioxidant activity of the crude extracts of drumstick tree (Moringa oleifera Lam.) and sweet broomweed (Scoparia dulcis L.) leaves. Polish Journal of Food and Nutrition Science, 57: 203-208

Park H, Cha H. 2008. Differences of Flavonols Profiles in Various Grape Cultivars Separated by High Performance Liquid Chromatography. Horticulture, Environment and Biotechnology, 49(1): 35-41.

Singleton VL, Rossi JR. 1965. Colorimetry of total phenolics with phosphomolybdic-phosphotungstic acid reagents, American Journal of Enology and Viticulture, 16(3): 144158.

Tang YL, Chan SW. 2014. A review of the pharmacological effects of piceatannol on cardiovascular diseases. Phytother Res 28: 1581-1588. 